\title{
A longitudinal analysis of the epidemiology and economic impact of inpatient admissions for chronic pancreatitis in the United States
}

\author{
Asim Shuja a , Asad Ur Rahman ${ }^{b}$, Wasseem Skef', Carmen Smothermand, Jian Guane, Miguel Malespin ${ }^{a}$, \\ Silvio W. de Melo Jra \\ University of Florida College of Medicine, Jacksonville; Cleveland Clinic Foundation, Florida; University of Illinois at \\ Chicago College of Medicine, USA
}

\section{Abstract}

a Division of Gastroenterology, University of Florida College of Medicine, Jacksonville (Asim Shuja, Miguel Malespin, Silvio W. de

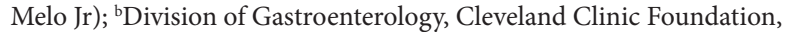
Florida (Asad Ur Rahman); 'Division of Gastroenterology, University of Illinois at Chicago College of Medicine (Wasseem Skef); ${ }^{\mathrm{d} C e n t e r}$ for Health Equity and Quality Research, University of Florida College of Medicine, Jacksonville (Carmen Smotherman); ${ }^{~}$ Department of Medicine, Florida Hospital, Orlando (Jian Guan), USA

\section{Conflict of Interest: None}

Correspondence to: Asim Shuja, MD, 4555 Emerson Street, Suite 300, Jacksonville, FL, 32207, USA, e-mail: asim.shuja@jax.ufl.edu

Received 23 January 2018; accepted 13 March 2018; published online 27 April 2018

DOI: https://doi.org/10.20524/aog.2018.0262

\section{Introduction}

Chronic pancreatitis (CP) is a chronic, progressive disease characterized by irreversible inflammatory scarring and fibrosis of the pancreas with resultant loss of exocrine and endocrine function [1]. Amongst numerous causative factors, alcohol remains the leading cause of CP in the United States and the rest of the developed world [2]. Based on data from Olmsted County, the incidence and prevalence ratios in the United States are estimated at 4.05 and 41.76 cases per 100,000 persons, respectively, with a higher incidence reported in men [3]. The most common clinical manifestation is abdominal pain, which can lead to recurrent hospital admission and possible interventions. In fact, more than $90 \%$ of patients 
with $\mathrm{CP}$ are hospitalized at least once in their lifetime for pain [4]. CP can also lead to numerous complications, including pancreatic insufficiency, local pancreatic and extra-pancreatic complications or malignancy, which may also require inpatient care and intervention [5].

The negative impact of CP on patients is well documented, with a significant reduction in health-related quality of life [6]. Furthermore, the effects on workplace participation are substantial, with only $37 \%$ reporting current employment in a multicenter survey [7]. However, data on hospitalization rates and associated costs in the United States are scarce. Previous data suggest that CP accounts for 11 and 8.1 per 100,000 population annual Emergency Department visits and hospital admissions, respectively, in the United States [8,9]. Furthermore, although it is an infrequent cause of hospitalization in comparison to other gastrointestinal disorders, the direct costs of inpatient hospitalization for CP are exorbitant, with an aggregate annual cost of $\$ 150$ million [9]. The aim of this current study was to assess changes in rate and temporal trends in the cost of inpatient admissions for a primary diagnosis of CP in the United States from 1997-2014.

\section{Materials and methods}

\section{Study design and date source}

We conducted a cross-sectional analysis of data from 1997-2014 using the National Inpatient Sample (NIS). This data set provides hospital administrative data through the Healthcare Cost and Utilization Project (HCUP), sponsored by the Agency for Healthcare Research and Quality. The NIS data were subject to a data use agreement. The NIS database is the largest publicly available all-payer inpatient care database in the United States and contains data from approximately 8 million hospital stays every year. The 1997 NIS database contains a total of approximately 7.1 million records drawn from 22 states. The 2014 NIS database contains a total of about 8 million records drawn from 45 states and includes information from 1051 hospitals. The NIS sampling frame covers $>95 \%$ of the United States population and $94 \%$ of all community hospital discharges. This study was exempt from Institutional Board Review.

\section{Identification of CP hospitalizations}

We identified all hospitalized patients aged $\geq 1$ year discharged with CP (ICD-9-CM discharge code 577.1) as primary diagnosis.

\section{Variables recorded}

The patient demographics analyzed included age and sex. Hospital characteristics included location (Northeast, Midwest, South, and West, and metropolitan vs. non-metropolitan), type (teaching vs. non-teaching), and bed size (small, medium, and large). According to the HCUPnet definition, an area is considered to be metropolitan if the population is at least 50,000 people, whereas an area with a population of less than 50,000 is considered non-metropolitan. A hospital is considered to be a teaching hospital if the American Hospital Association Annual Survey indicates that it has an American Medical Associationapproved residency program, is a member of the Council of Teaching Hospitals, or has a ratio of full-time equivalent interns and/or residents to beds of $>0.25$. Hospital bed size varies depending on the hospital's location and teaching status. Small hospitals range from 1-50 beds, medium hospitals range from $50-199$ beds, and large hospitals have more than 200 beds. The payer status for all admissions was also considered and divided into categories of Medicare, Medicaid, private insurance, uninsured, and other. "Hospital Charges" are defined as the amount the hospital charged for the patient's entire hospital stay, but they do not include professional (physician) fees. As per NIS, "aggregate charges" or the "national bill" are defined as the sum of all charges for all hospital stays in the United States and "length of stay" as the number of nights the patient remained in the hospital per stay.

\section{Statistical analysis}

Descriptive summaries were frequencies and percentages for categorical variables and means and standard errors for numeric variables. Rates of CP per 10,000 admissions were calculated by dividing the total number of patients with $\mathrm{CP}$ as primary discharge diagnosis by the total number of all discharges listed for each year. The Pearson chi-square test was used to compare proportions between 1997 and 2014. Relative risk ratios (RR), along with their 95\% confidence intervals (CI) comparing 1997-2014 were estimated. Trends across different demographic groups were analyzed using the CochranArmitage trend test. Regression analysis (simple linear regression model) was used to assess trends over the years (1997-2014) for the number of discharges for CP, LOS, and charges. Annual charges reported are the raw charges adjusted for the long-term average healthcare annual inflation rate (Bureau of Labor Statistics: http://data.bls.gov/) of $2.39 \%$, so that all dollar values relate to 2014 dollars. If the trend appeared to be non-linear, the natural logarithmic transformation was applied to the variable to linearize the relationship between the variable and time. Yearly changes were estimated using the resulting regression equation. All analyses were done using $\mathrm{SAS}^{\circledast}$ for Windows Version 9.4.

\section{Results}

\section{Number and cost of CP discharges}

The total number of hospital discharges with a primary diagnosis of CP decreased by 41.5\%, from 21,815 in 1997 to $12,770$ in $2014(\mathrm{P}<0.001)$ (Fig. 1$)$. The risk of hospital discharge 
for CP in 2014 was half of the risk of hospital discharge for CP in 1997 (relative risk [RR] 0.55, 95\%CI 0.54-0.56; $\mathrm{P}<0.0001$ ). The rate of hospital discharges for $\mathrm{CP}$ as a primary diagnosis decreased from 6.5/10,000 discharges to 3.6/10,000 discharges. In a given year, the number of inpatient $\mathrm{CP}$ diagnoses decreased, on average, by $3.3 \%(95 \%$ CI $2.2-4.6$; $\mathrm{P}<0.0001)$ of the number of diagnoses made in the previous year.

The average LOS decreased by $21.2 \%$ from 6.2 days in 1997 to 4.9 days in $2014(\mathrm{P}<0.0001)$ (Fig. 2). There was a significant decreasing trend for the average LOS. In a given year, the average LOS was estimated to be decreased, on average, by $1.4 \%$ (95\% CI 1.2-1.6, $\mathrm{P}<0.0001$ ) of the average LOS in the previous year.

Despite the decrease in the average LOS, the mean total charges for CP-related hospital admissions increased substantially between 1997 and 2014. Mean hospital charges per patient increased by $308.5 \%$, from $\$ 12,725$ (adjusted for inflation) in 1997 to $\$ 39,260$ in $2014(\mathrm{P}<0.001)$ (Fig. 3). The average cost of hospitalization (adjusted for inflation) where $\mathrm{CP}$ was the primary diagnosis increased every year by $4.9 \%$ (95\%CI 4.5-5.4; $\mathrm{P}<0.0001$ ), and the average aggregate charges (adjusted) increased every year by $1.7 \%$ (95\%CI $0.3-3.1 ; \mathrm{P}=0.022)$ (Fig. 4).

\section{CP discharges by patient characteristics}

In both years 1997 and 2014, the rate of discharges for CP was higher for the 45-64 years of age group (both $\mathrm{P}<0.0001$, Table 1). The risk of a discharge for CP significantly increased from 19972014 for the 1-17 year age group (RR 1.518, 95\%CI 1.516-1.520; $\mathrm{P}<0.0001$ ), while it significantly decreased over time for all the other age groups: $18-44$ years (RR 0.4958, 95\%CI 0.4957-0.4960;

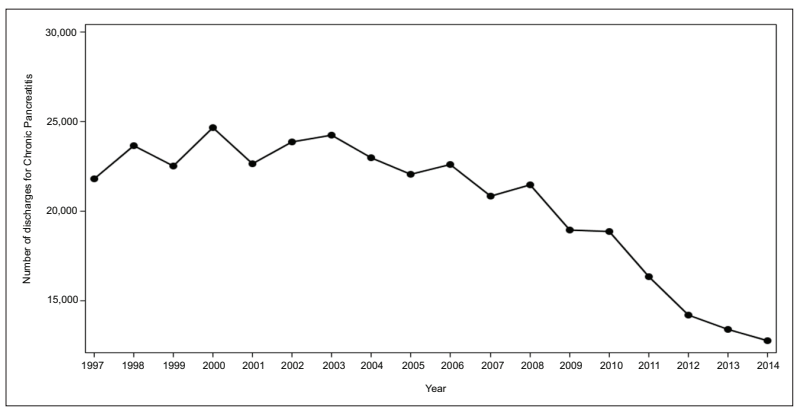

Figure 1 Number of discharges for chronic pancreatitis

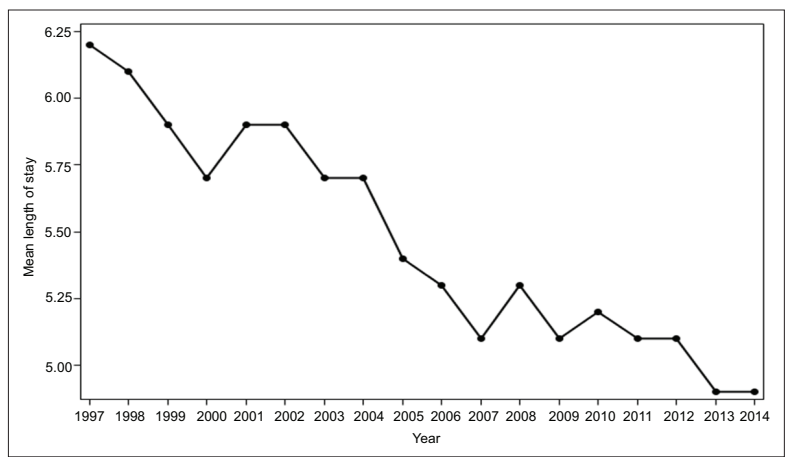

Figure 2 Mean length of stay for patients with chronic pancreatitis
$\mathrm{P}<0.001), \quad 45-64$ years $(\mathrm{RR} \quad 0.5406,95 \% \mathrm{CI} \quad 0.5404-0.5408$; $\mathrm{P}<0.0001$ ), 65-84 years (RR 0.4427, 95\%CI 0.4424-0.4430; $\mathrm{P}<0.001$ ), and $85+$ years age group (RR 0.2942 , 95\%CI 0.2936$0.2947 ; \mathrm{P}<0.001)$. The mean age for patients diagnosed with $\mathrm{CP}$ did not differ between 1997 and 2014 ( $\mathrm{P}=0.190$, Table 1).

The rate of CP was higher in males in both 1997 and 2014, decreasing from $8.03 / 10,000$ discharges in 1997 to $4.30 / 10,000$ discharges in 2014 (RR 0.5354, 95\% CI 0.5350-0.5353; $\mathrm{P}<0.001$ ). A decrease was also found in females, from 5.54/10,000 discharges in 1997 to $3.09 / 10,000$ discharges in 2014 (Table 1, RR 0.5581, 95\% CI 0.5579-0.5583; $\mathrm{P}<0.001$ ).

The rate of discharges for CP was higher for uninsured patients compared with all the other categories of insurance in both 1997 and $2014(\mathrm{P}<0.0001)$, with a significant decrease from 1997-2014 (RR 0.5295, 95\%CI 0.5295-0.5303; $\mathrm{P}<0.0001$ ). The rate of CP significantly decreased from 1997-2014 in all the other insurance categories (Table 1: Medicare RR 0.5503, 95\%CI 0.5501-0.5506; Medicaid RR 0.5225, 95\%CI 0.52230.5227; Private RR 0.5732, 95\%CI 0.5729-0.5734; other insurances RR 0.3902, 95\%CI 0.3902-0.3911; all $\mathrm{P}<0.0001$ ), and for patients without low income (RR 0.5487, 95\%CI 0.5485-0.5488; $\mathrm{P}<0.0001)$.

\section{CP discharges by hospital characteristics}

In 1997, the distribution of discharge rates for CP was different across various regions, with the highest rate in the

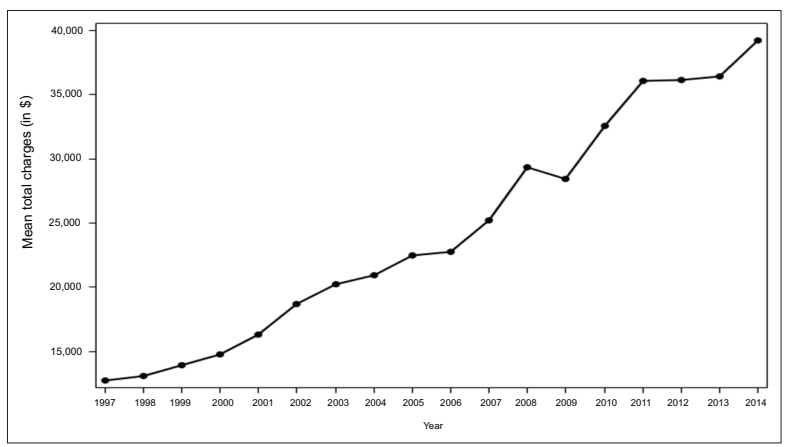

Figure 3 Mean total charges for patients with chronic pancreatitis

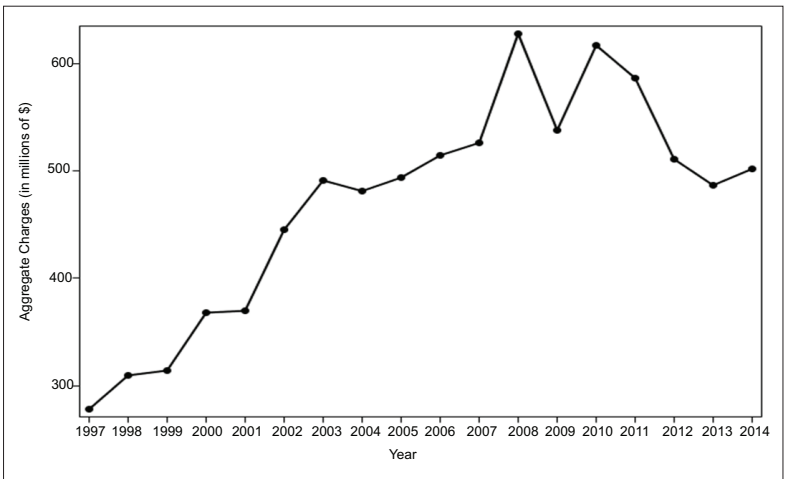

Figure 4 The overall aggregate charges with a primary diagnosis of chronic pancreatitis 
4 A. Shuja et al

Table 1 Number and rate of discharges with chronic pancreatitis (CP) by patient and hospital characteristics in 1997 and 2014 *

\begin{tabular}{|c|c|c|c|c|c|c|c|}
\hline \multirow[t]{3}{*}{ Category } & \multirow{3}{*}{$\begin{array}{l}\text { Categorical } \\
\text { variable }\end{array}$} & \multirow{2}{*}{$\begin{array}{c}1997 \\
\mathrm{CP}\end{array}$} & \multirow{2}{*}{$\begin{array}{c}2014 \\
\mathrm{CP}\end{array}$} & \multirow{2}{*}{$\begin{array}{l}1997 \\
\text { Total }\end{array}$} & \multirow{2}{*}{$\begin{array}{l}2014 \\
\text { Total }\end{array}$} & \multirow{3}{*}{$\begin{array}{c}1997 \\
\begin{array}{c}\text { CP per 10,000 } \\
\text { admissions }\end{array}\end{array}$} & \multirow{3}{*}{$\begin{array}{c}2014 \\
\begin{array}{c}\text { CP per 10,000 } \\
\text { admissions }\end{array}\end{array}$} \\
\hline & & & & & & & \\
\hline & & $(\mathrm{N}, \%)$ & $(\mathrm{N}, \%)$ & $(\mathrm{N}, \%)$ & $(\mathrm{N}, \%)$ & & \\
\hline \multicolumn{2}{|c|}{ All discharges } & 21,815 & 12,770 & $33,230,554$ & $35,358,818$ & 6.56 & 3.61 \\
\hline \multicolumn{2}{|c|}{ Mean age, years (SE) } & $\begin{array}{l}48.59 \\
(0.36)\end{array}$ & $\begin{array}{l}48.19 \\
(0.33)\end{array}$ & $46.9(0.37)$ & $48.55(0.20)$ & & \\
\hline \multirow[t]{7}{*}{ Age group } & $<1$ & $\dagger$ & $\dagger$ & $\begin{array}{l}4,263,624 \\
(13)\end{array}$ & $\begin{array}{l}4,247,755 \\
\quad(12)\end{array}$ & & \\
\hline & $1-17$ & $311(1)$ & $360(3)$ & $1,766,699(5)$ & $1,347,359(4)$ & 1.76 & 2.67 \\
\hline & $18-44$ & $\begin{array}{c}9,544 \\
(44)\end{array}$ & $\begin{array}{c}4,545 \\
(36)\end{array}$ & $\begin{array}{c}9,074,102 \\
(27)\end{array}$ & $\begin{array}{c}8,714,895 \\
\quad(25)\end{array}$ & 10.51 & 5.21 \\
\hline & $45-64$ & $\begin{array}{c}8,371 \\
(38)\end{array}$ & $\begin{array}{c}6,330 \\
(50)\end{array}$ & $\begin{array}{l}6,226,540 \\
(19)\end{array}$ & $\begin{array}{c}8,709,298 \\
(25)\end{array}$ & 13.44 & 7.26 \\
\hline & $65-84$ & $\begin{array}{c}3,168 \\
(15)\end{array}$ & $\begin{array}{c}1,380 \\
(11)\end{array}$ & $\begin{array}{c}9,644,446 \\
(29)\end{array}$ & $\begin{array}{l}9,490,054 \\
\quad(27)\end{array}$ & 3.28 & 1.45 \\
\hline & $85+$ & $417(2)$ & $155(1)$ & $2,245,807(7)$ & $2,837,716(8)$ & 1.85 & 0.54 \\
\hline & Missing & $\dagger$ & $\dagger$ & 9,336 & 11,740 & & \\
\hline \multirow[t]{3}{*}{ Sex } & Male & $\begin{array}{c}10,956 \\
(50)\end{array}$ & $\begin{array}{c}6,495 \\
(51)\end{array}$ & $\begin{array}{c}13,632,763 \\
(41)\end{array}$ & $\begin{array}{c}15,095,708 \\
(43)\end{array}$ & 8.03 & 4.3 \\
\hline & Female & $\begin{array}{c}10,859 \\
(50)\end{array}$ & $\begin{array}{c}6,265 \\
(49)\end{array}$ & $\begin{array}{c}19,593,669 \\
(59)\end{array}$ & $\begin{array}{l}20,255,555 \\
\quad(57)\end{array}$ & 5.54 & 3.09 \\
\hline & Missing & $\dagger$ & $\dagger$ & 4,122 & 7,555 & & \\
\hline \multirow[t]{6}{*}{ Payer } & Medicare & $\begin{array}{c}6,439 \\
(30)\end{array}$ & $\begin{array}{l}4,050 \\
(32)\end{array}$ & $\begin{array}{c}12,070,265 \\
(36)\end{array}$ & $\begin{array}{c}13,795,116 \\
(39)\end{array}$ & 5.33 & 2.93 \\
\hline & Medicaid & $\begin{array}{c}4,768 \\
(22)\end{array}$ & $\begin{array}{c}3,655 \\
(29)\end{array}$ & $\begin{array}{l}5,448,491 \\
\quad(16)\end{array}$ & $\begin{array}{l}7,993,545 \\
(23)\end{array}$ & 8.75 & 4.57 \\
\hline & $\begin{array}{l}\text { Private } \\
\text { insurance }\end{array}$ & $\begin{array}{c}7,337 \\
(34)\end{array}$ & $\begin{array}{c}3,555 \\
(28)\end{array}$ & $\begin{array}{c}12,814,864 \\
(39)\end{array}$ & $\begin{array}{c}10,833,048 \\
(31)\end{array}$ & 5.72 & 3.28 \\
\hline & Uninsured & $\begin{array}{c}2,115 \\
(10)\end{array}$ & $\begin{array}{l}1,145 \\
(9)\end{array}$ & $1,615,542(5)$ & $1,650,461(5)$ & 13.09 & 6.93 \\
\hline & Other & $\begin{array}{c}1,071 \\
(5)\end{array}$ & $355(3)$ & $1,201,195(4)$ & $1,019,269(3)$ & 8.91 & 3.48 \\
\hline & Missing & $86(0.4)$ & $\dagger$ & $80,196(0.2)$ & $67,380(0.2)$ & & \\
\hline \multicolumn{8}{|c|}{ Median income for zip code } \\
\hline & $\begin{array}{l}\text { Low }(\$ 0- \\
35,999)\end{array}$ & $\begin{array}{c}7,878 \\
(36)\end{array}$ & $\begin{array}{l}4,355 \\
(34)\end{array}$ & $\begin{array}{c}10,701,917 \\
(32)\end{array}$ & $\begin{array}{l}10,244,655 \\
(29)\end{array}$ & 7.36 & 4.25 \\
\hline & $\begin{array}{l}\text { Not low } \\
(\$ 36,000+)\end{array}$ & $\begin{array}{c}12,605 \\
(58)\end{array}$ & $\begin{array}{l}8,150 \\
(64)\end{array}$ & $\begin{array}{c}20,659,229 \\
(62)\end{array}$ & $\begin{array}{c}24,344,858 \\
(69)\end{array}$ & 6.1 & 3.34 \\
\hline & Missing & $\begin{array}{c}1,333 \\
(6)\end{array}$ & $265(2)$ & $1,869,408(6)$ & $769,305(2)$ & & \\
\hline \multicolumn{8}{|c|}{ Patient residence } \\
\hline & $\begin{array}{l}\text { Large central } \\
\text { metro }\end{array}$ & $\dagger$ & $\begin{array}{c}3,665 \\
(29)\end{array}$ & $\dagger$ & $\begin{array}{c}10,701,427 \\
(30)\end{array}$ & $\mathrm{NC}$ & 3.42 \\
\hline & Suburbs & $\dagger$ & $\begin{array}{c}2,825 \\
(22)\end{array}$ & $\dagger$ & $\begin{array}{c}8,415,991 \\
(24)\end{array}$ & NC & 3.35 \\
\hline
\end{tabular}

(Contd...) 
Table 1 (Continued)

\begin{tabular}{|c|c|c|c|c|c|c|c|}
\hline \multirow[t]{6}{*}{ Category } & \multirow{3}{*}{$\begin{array}{l}\text { Categorical } \\
\text { variable }\end{array}$} & \multirow{2}{*}{$\begin{array}{l}1997 \\
\mathrm{CP}\end{array}$} & \multirow{2}{*}{$\begin{array}{c}2014 \\
\mathrm{CP}\end{array}$} & \multirow{2}{*}{$\begin{array}{l}1997 \\
\text { Total }\end{array}$} & \multirow{2}{*}{$\begin{array}{l}2014 \\
\text { Total }\end{array}$} & \multirow{3}{*}{$\begin{array}{c}1997 \\
\begin{array}{c}\text { CP per 10,000 } \\
\text { admissions }\end{array}\end{array}$} & \multirow{3}{*}{$\begin{array}{c}2014 \\
\begin{array}{c}\text { CP per 10,000 } \\
\text { admissions }\end{array}\end{array}$} \\
\hline & & & & & & & \\
\hline & & $(\mathrm{N}, \%)$ & $(\mathrm{N}, \%)$ & $(\mathrm{N}, \%)$ & $(\mathrm{N}, \%)$ & & \\
\hline & $\begin{array}{l}\text { Medium and } \\
\text { small metro }\end{array}$ & $\dagger$ & $\begin{array}{c}4,095 \\
(32)\end{array}$ & $\dagger$ & $\begin{array}{c}10,389,229 \\
(29)\end{array}$ & $\mathrm{NC}$ & 3.94 \\
\hline & $\begin{array}{l}\text { Micropolitan } \\
\text { and OnCore }\end{array}$ & $\dagger$ & $\begin{array}{c}2,120 \\
(17)\end{array}$ & $\dagger$ & $\begin{array}{l}5,684,722 \\
(16)\end{array}$ & NC & 3.72 \\
\hline & Missing & $\dagger$ & $65(1)$ & $\dagger$ & $167,450(0.5)$ & & \\
\hline \multicolumn{8}{|c|}{ Teaching status } \\
\hline & Nonteaching & $\begin{array}{c}9,645 \\
(44)\end{array}$ & $\begin{array}{l}4050 \\
(32)\end{array}$ & $\begin{array}{l}4,857,604 \\
\quad(15)\end{array}$ & $\begin{array}{l}12,587,452 \\
(36)\end{array}$ & 19.85 & 3.21 \\
\hline & Teaching & $\begin{array}{c}12,170 \\
(56)\end{array}$ & $\begin{array}{r}8720 \\
(68)\end{array}$ & $\dagger$ & $\begin{array}{c}22,771,366 \\
(64)\end{array}$ & $\mathrm{NC}$ & 3.82 \\
\hline \multirow[t]{4}{*}{ Owner } & Government & $\begin{array}{c}4,390 \\
(20)\end{array}$ & $\begin{array}{c}1,905 \\
(15)\end{array}$ & $\begin{array}{c}4,707,979 \\
(14)\end{array}$ & $\begin{array}{l}4,310,458 \\
\quad(12)\end{array}$ & 9.32 & 4.41 \\
\hline & $\begin{array}{l}\text { Private, not- } \\
\text { for-profit }\end{array}$ & $\begin{array}{c}14,877 \\
(68)\end{array}$ & $\begin{array}{c}9,050 \\
(71)\end{array}$ & $\begin{array}{l}23,924,271 \\
(72)\end{array}$ & $\begin{array}{l}25,831,562 \\
\quad(73)\end{array}$ & 6.21 & 3.5 \\
\hline & $\begin{array}{l}\text { Private, for- } \\
\text { profit }\end{array}$ & $\begin{array}{c}2,454 \\
(11)\end{array}$ & $\begin{array}{c}1,815 \\
(14)\end{array}$ & $\begin{array}{c}4,464,111 \\
\quad(13)\end{array}$ & $\begin{array}{l}5,216,798 \\
(15)\end{array}$ & 5.49 & 3.47 \\
\hline & Missing & $95(0.4)$ & $\dagger$ & $\dagger$ & $\dagger$ & & \\
\hline \multirow[t]{3}{*}{ Location } & $\begin{array}{l}\text { Non- } \\
\text { metropolitan }\end{array}$ & $\begin{array}{c}3,067 \\
(14)\end{array}$ & $\dagger$ & $\dagger$ & $\dagger$ & NC & $\mathrm{NC}$ \\
\hline & Metropolitan & $\begin{array}{c}18,654 \\
(86)\end{array}$ & $\dagger$ & $\dagger$ & $\dagger$ & NC & $\mathrm{NC}$ \\
\hline & Missing & $95(0.4)$ & $\dagger$ & $\dagger$ & $\dagger$ & & \\
\hline \multirow[t]{4}{*}{ Bed size } & Small & $\begin{array}{c}3,865 \\
(18)\end{array}$ & $\begin{array}{c}2,230 \\
(17)\end{array}$ & $\begin{array}{l}5,284,288 \\
\quad(16)\end{array}$ & $\begin{array}{c}6,553,063 \\
(19)\end{array}$ & 7.31 & 3.4 \\
\hline & Medium & $\begin{array}{c}7,567 \\
(35)\end{array}$ & $\begin{array}{c}3,635 \\
(28)\end{array}$ & $\begin{array}{c}11,047,425 \\
(33)\end{array}$ & $\begin{array}{c}10,398,925 \\
(29)\end{array}$ & 6.84 & 3.49 \\
\hline & Large & $\begin{array}{c}10,288 \\
(47)\end{array}$ & $\begin{array}{c}6,905 \\
(54)\end{array}$ & $\begin{array}{l}16,764,648 \\
(55)\end{array}$ & $\begin{array}{c}18,406,830 \\
(52)\end{array}$ & 6.13 & 3.75 \\
\hline & Missing & $95(0.4)$ & $\dagger$ & * & * & & \\
\hline \multirow[t]{4}{*}{ Region } & Northeast & $\begin{array}{c}4,376 \\
(20)\end{array}$ & $\begin{array}{c}1,975 \\
(15)\end{array}$ & $\begin{array}{c}6,784,405 \\
(20)\end{array}$ & $\begin{array}{c}6,623,697 \\
(19)\end{array}$ & 6.45 & 2.98 \\
\hline & Midwest & $\begin{array}{c}4,959 \\
(23)\end{array}$ & $\begin{array}{c}3,220 \\
(25)\end{array}$ & $\begin{array}{c}7,740,346 \\
(23)\end{array}$ & $\begin{array}{l}7,942,913 \\
(22)\end{array}$ & 6.4 & 4.05 \\
\hline & South & $\begin{array}{c}8,137 \\
(37)\end{array}$ & $\begin{array}{c}5,410 \\
(42)\end{array}$ & $\begin{array}{c}12,373,424 \\
(37)\end{array}$ & $\begin{array}{c}13,774,248 \\
(39)\end{array}$ & 6.57 & 3.92 \\
\hline & West & $\begin{array}{c}4,343 \\
(20)\end{array}$ & $\begin{array}{c}2,165 \\
(17)\end{array}$ & $\begin{array}{c}6,332,379 \\
(19)\end{array}$ & $\begin{array}{c}7,017,960 \\
(20)\end{array}$ & 6.85 & 3.08 \\
\hline
\end{tabular}

${ }^{*}$ Some percentages do not add up to $100 \%$ because of missing data; $\uparrow$ Data not available

$S E$, standard error; NC, not calculated

West $(6.85 / 10,000$ discharges), followed by the Midwest (6.40/10,000 discharges), Northeast (6.45/10,000 discharges), and South $(6.57 / 10,000$ discharges, $\mathrm{P}<0.0001)$. A difference across regions was also found in 2014, but the highest rate of discharges for $\mathrm{CP}$ was found in the Midwest region (4.05/10,000 discharges), followed by the South $(3.92 / 10,000$ discharges), West (3.08/10,000 discharges) and Northeast (2.98/10,000 discharges, $\mathrm{P}<0.0001)$. Within each region, the risk of CP decreased significantly from 1997-2014, with the smallest decrease in the Midwest (RR 0.6325. 95\%CI 0.6325$0.6330 ; \mathrm{P}<0.0001$ ), followed by the South (RR $0.5970,95 \% \mathrm{CI}$ 0.5970-0.5975; $\mathrm{P}<0.0001$ ), Northeast (RR 0.4623, 95\%CI 
0.4620-0.4625; $\mathrm{P}<0.0001$ ), and West (RR 0.4498, 95\%CI 0.4496-0.4500; $\mathrm{P}<0.0001$ ).

In 2014, patients were more likely to be diagnosed with CP in a teaching hospital (rate 3.82/10,000 discharges) compared to a non-teaching hospital (rate 3.21/10,000 discharges (RR 1.1902, 95\%CI 1.1897-1.1906; $\mathrm{P}<0.0001)$. No information was available for the total number of discharges in 1997 for teaching hospitals.

While in 1997 patients with CP were more likely to be diagnosed in a hospital with a small bed size (7.31/10,000 discharges, $\mathrm{P}<0.0001)$, in 2014 they were more likely to be diagnosed in a hospital with a large bed size $(3.75 / 10,000$ discharges, $\mathrm{P}<0.0001)$. The risk for CP significantly decreased from 1997-2014 for each hospital bed size (small RR 0.4653, 95\%CI 0.4650-0.4655, $\mathrm{P}<0.0001$; medium RR 0.5103, 95\%CI 0.5101-0.5105, $\mathrm{P}<0.0001$; and large RR 0.6113, 95\%CI 0.6111-0.6115, $\mathrm{P}<0.0001$ ).

Government hospitals had a higher frequency of CP (9.32/10,000 discharges in 1997, and 4.41/10,000 discharges in 2014). The risk of CP decreased from 1997-2014 in all three type of hospitals (Government RR 0.4740, 95\%CI 0.4737$0.4742, \mathrm{P}<0.0001$; Private non-profit RR 0.5634, 95\%CI 0.5633$0.5636, \mathrm{P}<0.0001$; and Private for profit $\mathrm{RR} 0.6329,95 \% \mathrm{CI}$ 0.6325-0.6333, $\mathrm{P}<0.0001)$.

\section{Discussion}

Pain is the primary symptom of CP. It is also the most common underlying reason for hospital admission in patients with CP [10]. Analgesic use should follow the guidelines set by the World Health Organization, since opioid analgesic dependence due to injudicious use can lead to a significant impact on the quality of life of patients and result in recurrent hospitalizations [11]. As the healthcare costs continue to rise, it is important to evaluate the burden of CP on our healthcare system. We utilized the NIS database, as its immense size produces an exceptional representative sample of the general US population.

Our results show that 18-44-year-old individuals comprised the majority of patients admitted with CP in 1997 (44\%), whereas the 45-64-year-old age group represented the majority in 2014 (50\%). This change may be attributed to the pathophysiology of CP as a progressive illness. It is likely that the same patients are now getting older and are joining the new age bracket.

However, between 1997 and 2014, the total number of hospital discharges with a primary diagnosis of CP decreased by $41.5 \%$. This decrease was observed in all age groups except for the 1-17-year-old individuals, where we observed an increase from 1.76 to 2.67 cases of CP per 10,000 admissions. We believe that the overall number of patients in this group is too small to generalize results for this age group. However, one possible explanation for this finding could be that pediatric gastroenterologists have become more aware of the diagnosis of $\mathrm{CP}$ in the pediatric population. Likewise, early patient transfer to larger tertiary medical centers where genetic testing (e.g., mutations in PRSS1, SPINK1) is readily available, may lead to an increase in the rate of diagnosis and hospitalization for CP [12].
We also observed a decline in the average LOS for patients in hospital from 6.2 days in 1997 to 4.9 days in 2014. This decrease is likely to be attributable to an improvement in pain control over time and an increased trend towards outpatient management. An increase of $4.9 \%$ was noted in average charges every year, and the average aggregateadjusted hospital charges increased by $1.7 \%$ every year. This is substantial, since the management of CP imposed an overall estimated cost of \$150 million in 2012 in the United States [9]. This increase is likely to have been driven by the increased availability of endoscopic procedures (such as endoscopic ultrasonography) used in the diagnosis and management of $\mathrm{CP}$, such as those used for pseudocyst drainage and celiac plexus neurolysis. Likewise, judicious use of expensive radiological studies, such as computed tomography and magnetic resonance cholangiopancreatography, could potentially add to the higher cost. Bliss et al showed that $10.8 \%$ of all patients who required hospitalization for CP between 2007 and 2013 underwent a CP-related surgical procedure. The total inpatient costs for patients requiring surgery was more than twice higher than for those who did not undergo surgery [13].

The patients' mean age showed no significant change between 1997 and 2014. Although the absolute number of $\mathrm{CP}$ discharges did not differ between males and females, men had a relatively higher number of discharges related to CP per 100,000 compared to women, since women were more likely to be hospitalized overall. Although the absolute number of hospital discharges related to CP for both men and women decreased from 1997-2014, there continues to be a relative disparity between the sexes. This is in part due to the fact that men have a higher incidence of CP than women, with some studies stating that it could be at least twice as high [14].

Medicare and Medicaid remained the payers for the majority of patients admitted to the hospital over the time period studied. In the uninsured population, 13.09 of every 10,000 admissions were attributed to CP in 1997; however, the number reduced to 6.93 per 10,000 in 2014 . Among all the insurance categories, this was highest relative number of admissions. This comes as no surprise, since the healthcare cost and utilization project from 2012 showed that pancreatic disorders were the ninth leading cause of hospital admissions among uninsured patients [15]. This is probably because patients in this category have difficulty completing adequate outpatient follow up.

A decline in the number of discharges was observed in all regions of the United States over time from 1997-2014. Although the Western region accounted for the highest number of discharges with CP per 10,000 (6.85) in 1997, the Midwest had the slowest decline and was found to be the leading region with discharges attributed to CP (4.05 compared to 3.05 in the Western region). This could be related to an higher prevalence of smoking and alcohol consumption in the Midwest compared to other regions of the United States [16,17]. However, in terms of absolute numbers, the South continued to have the greatest number of total patients admitted and discharged with CP (37\% in 1997 and 42\% in 2014).

Although we do not have data for total discharges in the teaching hospital setting in 1997, the absolute number of discharges related to CP increased from 56\% to 68\% from 1997 to 2014 . This proportion was similar to that observed in small 
and medium/large sized hospitals. This could be explained on the basis of an increased number of referrals to larger centers that have the capability to manage the complex needs of patients with CP, with procedures such as celiac plexus block.

As with all studies reflecting the burden of illnesses, our data had some limitations. As this is an administrative data set, it is reflective of the coding practices of each healthcare institution. It is likely that these results significantly underestimate the actual incidence of CP discharges, as patients' discharges may have been coded with an alternative diagnosis, such as acute pancreatitis. In addition, this data set does not control for errors during data entry. The NIS found that modifications in their hospital sampling strategy in 2012 may have decreased total hospitalization by $0.7 \%$ secondary to the exclusion of long-term acute-care hospitals. The degree to which these modifications affected the CP hospitalization counts for 20122014 is unknown. Likewise, we acknowledge that the NIS data set does not provide sufficient patient and hospital details to determine other factors that could explain the increased cost of admission.

In summary, our study is the first attempt to assess changes in frequency and temporal trends in the cost of inpatient admissions for a primary diagnosis of CP in the United States. Further studies would be needed in order to explain the increase in healthcare cost for patients with $\mathrm{CP}$, despite the decline seen in the number of discharges and LOS.

\section{Summary Box}

\section{What is already known:}

- Chronic pancreatitis (CP) is a chronic, debilitating disorder associated with multiple complications, frequently necessitating hospitalization

- Data on CP-related hospitalization rates and associated costs in the United States are scarce

\section{What the new findings are:}

- Between 1997 and 2014, the number of hospitalizations for patients with a primary discharge diagnosis of CP decreased by $41.5 \%$

- While the overall length of hospital stay decreased over that period, the cost associated with these hospitalizations has almost tripled

\section{References}

1. Conwell DL, Lee LS, Yadav D, et al. American pancreatic association practice guidelines in chronic pancreatitis: evidence-based report on diagnostic guidelines. Pancreas 2014;43:1143-1162.

2. Braganza JM, Lee SH, McCloy RF, McMahon MJ. Chronic pancreatitis. Lancet 2011;377:1184-1197.

3. Yadav D, Timmons L, Benson JT, Dierkhising RA, Chari ST. Incidence, prevalence, and survival of chronic pancreatitis: a population-based study. Am J Gastroenterol 2011;106:2192-2199.

4. Mullady DK, Yadav D, Amann ST, et al; NAPS2 Consortium. Type of pain, pain-associated complications, quality of life, disability and resource utilisation in chronic pancreatitis: a prospective cohort study. Gut 2011;60:77-84.

5. Ammann RW, Akovbiantz A, Largiader F, Schueler G. Course and outcome of chronic pancreatitis. Longitudinal study of a mixed medical-surgical series of 245 patients. Gastroenterology 1984;86:820-828.

6. Wehler M, Nichterlein R, Fischer B, et al. Factors associated with health-related quality of life in chronic pancreatitis. Am J Gastroenterol 2004;99:138-146.

7. Gardner TB, Kennedy AT, Gelrud A, et al. Chronic pancreatitis and its effect on employment and health care experience: results of a prospective American multicenter study. Pancreas 2010;39:498-501.

8. Yang AL, Vadhavkar S, Singh G, Omary MB. Epidemiology of alcohol-related liver and pancreatic disease in the United States. Arch Intern Med 2008;168:649-656.

9. Peery AF, Crockett SD, Barritt AS, et al. Burden of gastrointestinal, liver, and pancreatic diseases in the United States. Gastroenterology 2015;149:1731-1741.

10. Dennison AR, Garcea G. Economic burden of chronic pancreatitis and implications of total pancreatectomy and autologous islet cell transplantation. JOP 2015;16:517-526.

11. WHO. Cancer pain relief and palliative care: report of a WHO expert committee. Geneva: World Health Organization, 1990: technical report series 804 .

12. Kumar S, Ooi CY, Werlin S, et al. Risk factors associated with pediatric acute recurrent and chronic pancreatitis: lessons from INSPPIRE. JAMA Pediatr 2016;170:562-569.

13. Bliss, Lindsay A, Yang C, Eskander M, et al. Surgical management of chronic pancreatitis: current utilization in the United States. HPB (Oxford) 2015;17:804-810.

14. Lévy P, Domínguez-Muñoz E, Imrie C, Löhr M, Maisonneuve P. Epidemiology of chronic pancreatitis: burden of the disease and consequences. United European Gastroenterol J 2014;2:345-354.

15. Lopez-Gonzalez L, Pickens GT, Washington R, Weiss AJ. Characteristics of Medicaid and uninsured hospitalizations, 2012. https://www.hcup-us.ahrq.gov/reports/statbriefs/sb182-MedicaidUninsured-Hospitalizations-2012.jsp.

16. National Survey on Drug Use and Health, 2014. https://www.cdc. gov/tobacco/disparities/geographic/index.htm.

17. CDC. Prevalence of binge drinking among US adults, 2015. https:// www.cdc.gov/alcohol/data-stats.htm. 